\title{
Uterine Artery Laceration after Vacuum Delivery
}

\section{Laceração da Artéria Uterina após Parto Auxiliado por Ventosa}

\author{
Susana CORREIA COSTA ${ }^{1}$, Pedro VIANA PINTO1,2, Paulo MORGADO ${ }^{3}$, Nuno MONTENEGRO ${ }^{1}$ \\ Acta Med Port 2021 Dec;34(12):864-867 • https://doi.org/10.20344/amp.13399
}

\section{ABSTRACT}

Post-partum hemorrhage is one of the leading causes of maternal mortality and it's etiology needs to be identified in order for adequate treatment to be provided. We report a case of a post-partum hemorrhage in a multiparous woman treated with selective coil packing embolization after identification of laceration of the right uterine artery's ascending branch. The patient was admitted to an intensive care unit in hemorrhagic hypovolemic shock and disseminated intravascular coagulation and underwent total hysterectomy due to infectious complications.

Keywords: Disseminated Intravascular Coagulation/etiology; Postpartum Hemorrhage; Uterine Artery Embolization; Vacuum Extraction, Obstetrical/adverse effects

\section{RESUMO}

A hemorragia pós-parto é uma das principais causas de mortalidade materna e a sua etiologia deve ser identificada para um tratamento adequado. Descrevemos um caso de hemorragia pós parto numa multípara tratada com embolização selectiva após identificação de uma laceração total do ramo ascendente da artéria uterina direita. A puérpera foi admitida na unidade de cuidados intensivos em choque hipovolémico hemorrágico e coagulação intravascular disseminada que culminou numa histerectomia abdominal por complicações infeciosas.

Palavras-chave: Coagulação Intravascular Disseminada/etiologia; Embolização da Artéria Uterina; Extração Obstétrica por Aspiração/efeitos adversos; Hemorragia Pós-Parto

\section{INTRODUCTION}

Post-partum hemorrhage is one of the major causes of maternal mortality and is the most common reason for blood transfusion after delivery. ${ }^{1-3}$ According to the World Health Organization, post-partum hemorrhage accounts for approximately one-quarter of all maternal deaths globally and for approximately half of all post-partum deaths in lowincome countries. ${ }^{4}$ Post-partum hemorrhage that occurs in the first 24 hours after delivery is considered primary and is mostly due to uterine atony, genital tract lacerations, placental retention, abnormal placentation or coagulopathy. ${ }^{2,5-7}$

We present a rare case of right uterine and cervical laceration after vacuum-assisted delivery resulting in disseminated intravascular coagulopathy, treated with uterine artery embolization and hysterectomy

\section{CASE REPORT}

A 39-year-old woman with two previous vaginal deliveries and no history of undergoing major surgery was transferred to our tertiary hospital center, five hours after a vacuum-assisted delivery (due to fetal bradycardia, applied in Hodge's plane III), complicated with shoulder dystocia and repair of cervical laceration. She was admitted in refractory hemorrhagic hypovolemic shock (blood pressure 48/39 $\mathrm{mmHg}$, heart rate 180 beats per minute, oliguria, metabolic acidosis, hyperlactacidemia of $17.49 \mathrm{mmol} / \mathrm{L}$ ). After excluding, through physical examination, uterine atony, visible lac- eration of the birth canal and retained placenta fragments, selective angiography was performed, which identified a laceration of the ascending branch of the right uterine artery. Selective coil packing embolization was subsequently performed (Fig. 1).

In order to stabilize the disseminated intravascular coagulation and multi-organ dysfunction, the patient was admitted to an intensive care unit for two weeks and was on mechanical ventilation, aminergic support and had massive blood transfusion (28 units of red blood cells, 20 units of fresh frozen plasma, 11 platelet transfusions, $9 \mathrm{~g}$ of fibrinogen and $1000 \mathrm{IU}$ of antithrombin III). Due to a nosocomial infection by Extended Spectrum $\beta$ Lactamase-producing Klebsiella pneumoniae, the patient was also treated with intravenous ertapenem for seven days.

After discharge from the intensive care unit and because of the patient presented with a fever, clinical deterioration and purulent lochia, an abdominal and pelvic computed tomography was performed (Fig. 2). Infection of a right pelvic hematoma (two communicated loculi with transverse, anteroposterior and length dimensions of $15.1 \times 13.8 \times 18.1 \mathrm{~cm}$ and $7.3 \times 7.0 \times 6.9 \mathrm{~cm}$, the latter with gas bubbles, suggesting infection) with uterine fistula was suspected. A total abdominal hysterectomy with bilateral salpingectomy (Fig. 3) was performed, with right ureter catheterization in order to prevent iatrogenic injury.

\footnotetext{
1. Department of Gynaecology and Obstetrics. Centro Hospitalar Universitário São João. Porto. Portugal.

2. Anatomy Unit. Biomedicine Department. Faculdade de Medicina. Universidade do Porto. Porto. Portugal.

3. Department of Radiology. Centro Hospitalar Universitário São João. Porto. Portugal.

$\triangle$ Autor correspondente: Susana Correia Costa. susana.correia.costa@chsj.min-saude.pt

Recebido: 08 de janeiro de 2020 - Aceite: 07 de agosto de 2020 - First published: 12 de novembro de 2021 - Online issue published: 02 de dezembro de 202 Copyright $\odot$ Ordem dos Médicos 2021
} 


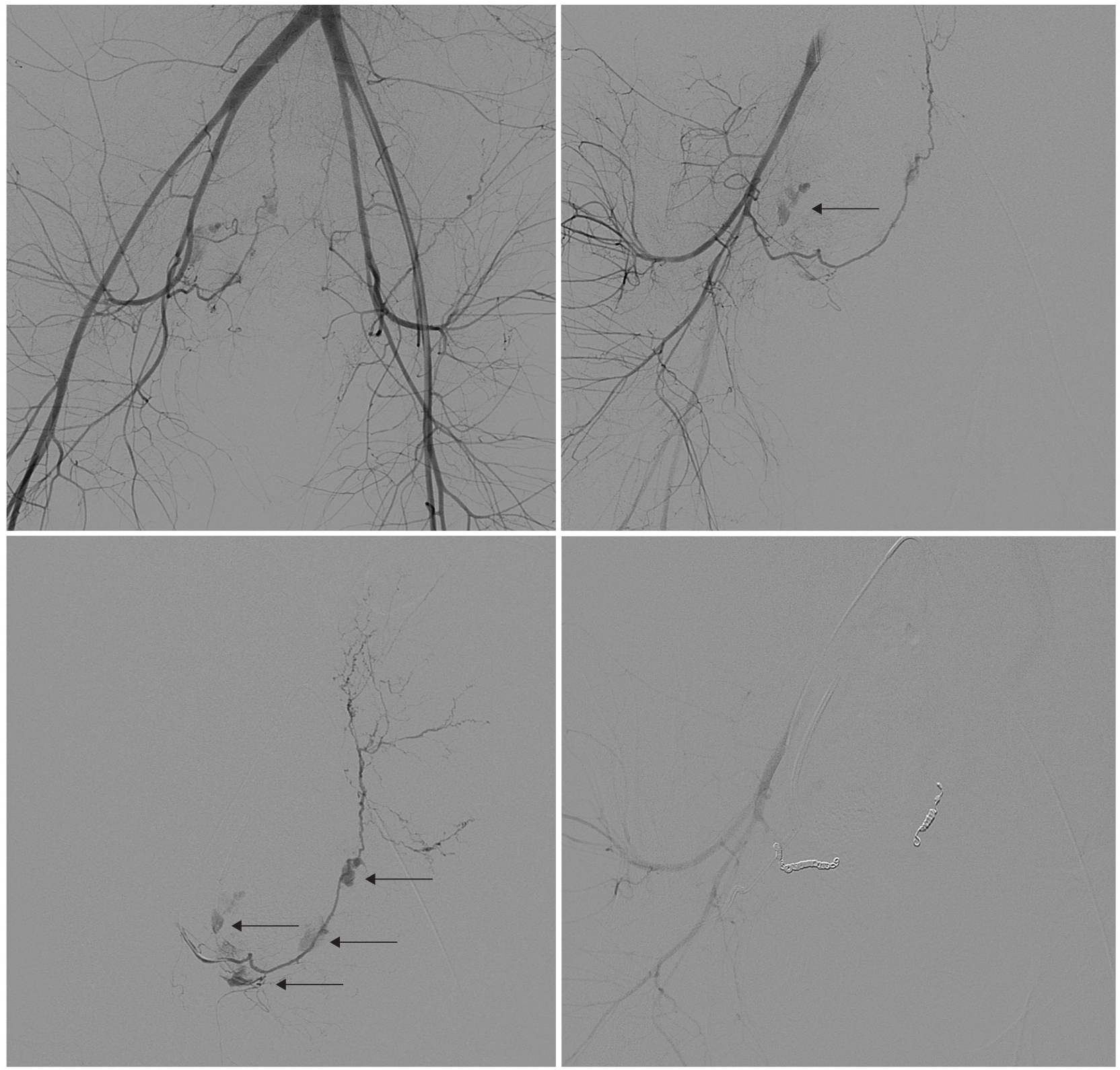

Figure 1 - Pelvic arteriogram, with multifocal laceration of horizontal and ascending branches of right uterine artery, with contrast extravasation (arrows), reflecting active bleeding

Histological and micro-bacteriological findings confirmed the diagnosis: a right cervical and uterine wall laceration with subsequent infection and necrosis (Fig. 4).

The post-operative period presented no further complications; the patient was treated with intravenous vancomycin and meropenem for seven days and was discharged home 30 days after giving birth and seven days after hysterectomy with complete clinical resolution, without any coagulation disorder, hemoglobin $8.8 \mathrm{~g} / \mathrm{dL}$, and indication for deep venous thrombosis prophylaxis for two more weeks. The ureteral catheter was removed on day 58 after surgery, without any intercurrences.

\section{DISCUSSION}

We described a rare case of right uterine and cervical laceration after vacuum-assisted delivery. Post-partum he- matomas, particularly intra-abdominal hematoma, are an unusual presentation of post-partum hemorrhage and can be caused by collapse of blood vessels following laceration, episiotomy or an operative delivery. ${ }^{8}$ Spontaneous uterine artery rupture is also a rare complication. ${ }^{9}$

Post-partum hemorrhage is an unpredictable emergency usually controlled by uterine massage, uterotonic agents or by surgical intervention in the event of persistent bleeding. ${ }^{10}$ Secondary disseminated coagulopathy often occurs in cases of massive post-partum hemorrhage as described in the literature. ${ }^{3}$

Pelvic transcatheter arterial embolization is a safe, effective and minimally invasive alternative to surgical intervention for severe post-partum hemorrhage refractory to conservative treatment measures, particularly in cases of uterine atony, genital tract tears and vaginal-perineal 

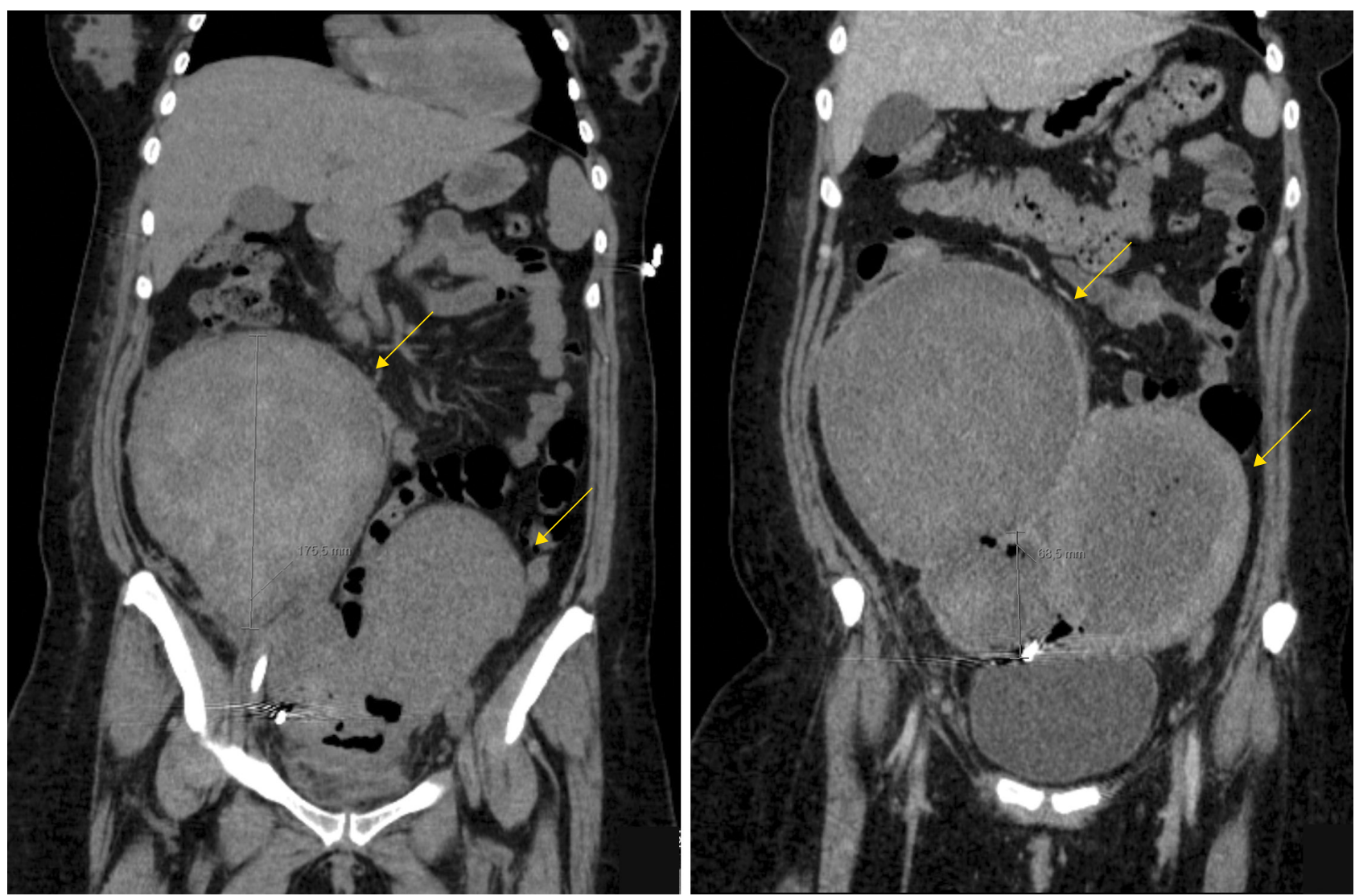

Figure 2 - Abdomin-pelvic computer tomography performed at day 20 of puerperium. A right pelvic hematoma with two communicated loculi (dimensions of $15.1 \times 13.8 \times 18.1 \mathrm{~cm}$ and $7.3 \times 7.0 \times 69 \mathrm{~cm}$ ) was identified (arrows).

hematoma, and may also preserve future fertility. 2,6,10,11 In this case, angiography revealed active bleeding based on the extravasation of contrast medium outside the vascular space, and a number of embolic materials could be used to occlude the bleeding vessel and avoid side effects associated with major surgery and anaesthesia. ${ }^{12}$ The success rate of transcatheter arterial embolization varies between $85 \%-100 \%$. $^{1,6,7,10,13}$ Complication rates related with arterial

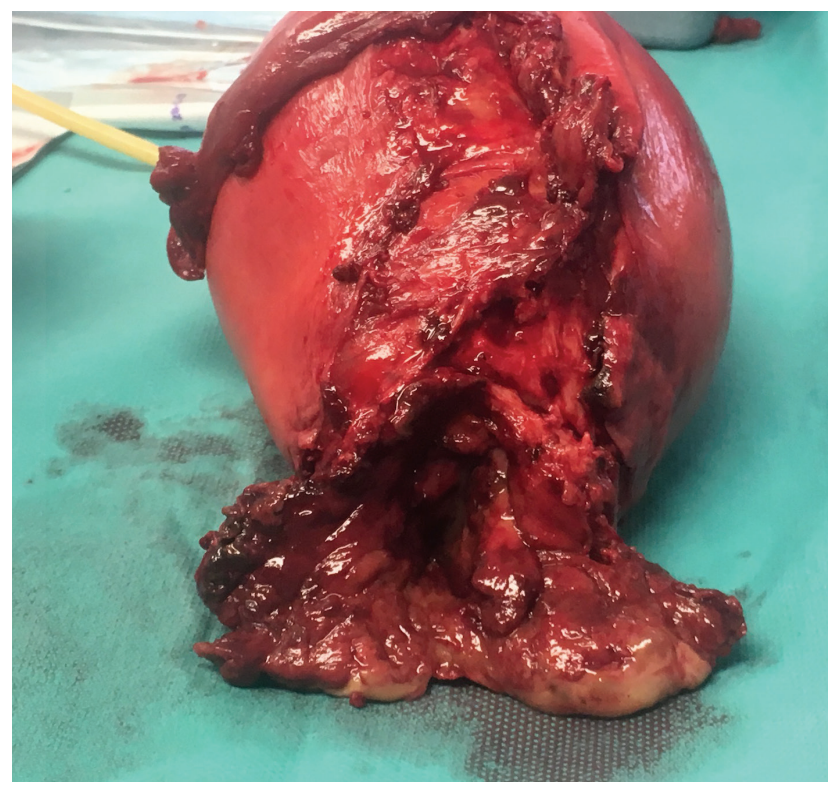

Figure 3 - Lateral view of hysterectomy specimen embolization are low, ranging between $6 \%-9 \%$, including post-embolization syndrome (transient fever, pelvic pain and nausea), intra-abdominal hematoma, uterine necrosis, artery dissection, lower limb ischemia, endometritis, amenorrhea and sepsis. ${ }^{11,13-15}$

We consider this case a success, as selective arterial embolization allowed hemorrhage control in an unstable patient with disseminated intravascular coagulopathy, thus

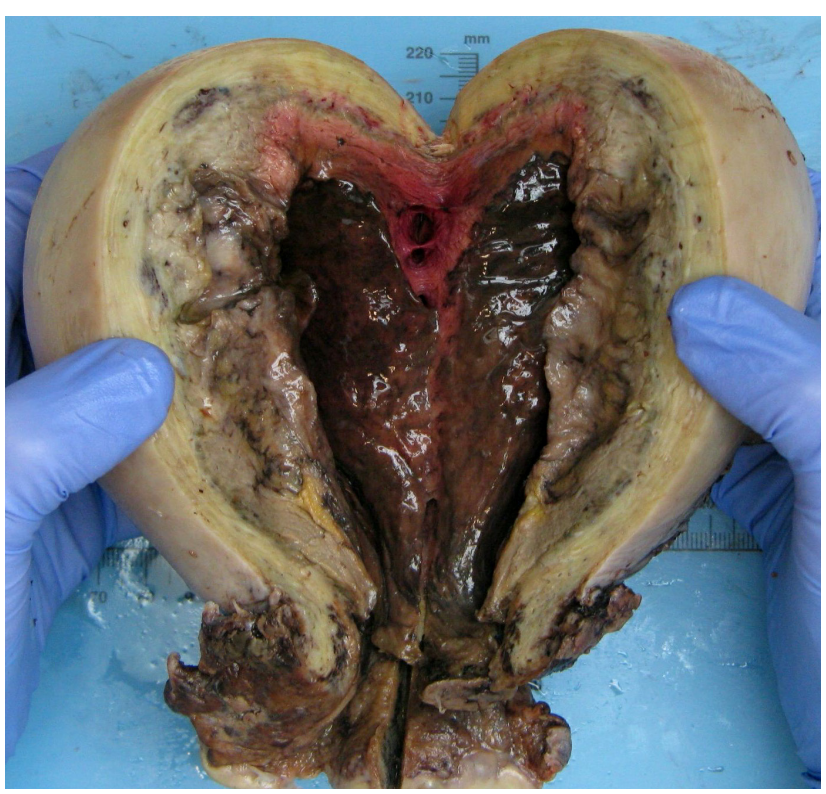

Figure 4 - Infection and necrosis of uterine wall 
minimizing the bleeding risks associated with major anesthetics and surgical procedures. The patient eventually underwent hysterectomy, but the surgery could be carried out in a safer environment and performed without any intercurrences.

This case reminds us of the importance of a multidisciplinary team (obstetrics, interventional radiology, intensive care unit, blood bank and urology) in a life-threating case. This multidisciplinary intervention, with a quick diagnosis and prompt treatment, was crucial to the patient's survival.

\section{AUTHORS CONTRIBUTION}

SCC: Draft of the paper. Acquisition and analysis of the medical information.

PVP: Significant contribution to the draft of the paper. Critical review.

PM: Selection of the illustrations. Critical review of the paper.

NM: Critical review of the paper.

\section{PROTECTION OF HUMANS AND ANIMALS}

The authors declare that the procedures were followed according to the regulations established by the Clinical Research and Ethics Committee and to the Helsinki Declaration of the World Medical Association updated in 2013.

\section{DATA CONFIDENTIALITY}

The authors declare having followed the protocols in use at their working center regarding patients' data publication.

\section{PATIENT CONSENT}

Obtained.

\section{COMPETING INTERESTS}

The authors have declared that no competing interests exist.

\section{FUNDING SOURCES}

This research received no specific grant from any funding agency in the public, commercial, or not-for-profit sectors.

9. Thakur M, Adekola HO, Asaad R, Gonik B. Secondary postpartum hemorrhage due to spontaneous uterine artery rupture after normal vaginal delivery managed by selective arterial embolization. AJP Rep. 2016;6:e442-4

10. Delotte J, Novellas S, Koh C, Bongain A, Chevallier P. Obstetrical prognosis and pregnancy outcome following pelvic arterial embolisation for post-partum hemorrhage. Eur J Obstet Gynecol Reprod Biol. 2009;145:129-32.

11. Poujade O, Ceccaldi PF, Davitian C, Amate P, Chatel P, Khater C, et al. Uterine necrosis following pelvic arterial embolization for post-partum hemorrhage: review of the literature. Eur J Obstet Gynecol Reprod Biol. 2013;170:309-14.

12. Lai BM, Shum JS, Chu CY, Lo SS, Lau KY. Predictors of the success and failure of emergency pelvic artery embolisation for primary postpartum haemorrhage: a 12-year review. Singapore Med J. 2017;58:272-8.

13. Ruiz Labarta FJ, Pintado Recarte MP, Alvarez Luque A, Joigneau Prieto L, Perez Martin L, Gonzalez Leyte M, et al. Outcomes of pelvic arterial embolization in the management of postpartum haemorrhage: a case series study and systematic review. Eur J Obstet Gynecol Reprod Biol. 2016;206:12-21.

14. Rafi J, Khalil H. Maternal morbidity and mortality associated with retroperitoneal haematomas in pregnancy. JRSM Open. 2018;9:2054270417746059.

15. Soro MP, Denys A, de Rham M, Baud D. Short \& long term adverse outcomes after arterial embolisation for the treatment of postpartum haemorrhage: a systematic review. Eur Radiol. 2017;27:749-62. 